Journal of Systems Science and Information

Aug., 2016, Vol. 4, No. 4, pp. 291-306

DOI: $10.21078 /$ JSSI-2016-291-16

\title{
Retrospective and Prospective Analysis on the Trends of China's Steel Production
}

\author{
Yanni XUAN \\ SEP Key Laboratory of Eco-Industry, Northeastern University, Shenyang 110819, China \\ E-mail: xuanyn.2006@163.com \\ Qiang YUE* \\ SEP Key Laboratory of Eco-Industry, Northeastern University, Shenyang 110819, China \\ E-mail: yueq@smm.neu.edu.cn
}

\begin{abstract}
Economic development has contributed to the rapid expansion of China's steel industry during the past two decades, which has resulted in numerous problems including increased energy consumption and excessive environmental pollution. This study examines changes in crude steel production, steel scrap consumption, energy consumption, $\mathrm{CO}_{2}$ emissions and steel stocks per capita from 2000 to 2014. Scenario analysis based on QGT equation is provided to accurately assess China's steel demand. Under three different scenarios, the peak of steel production and the variation trend of energy consumption, $\mathrm{CO}_{2}$ emissions, steel stocks per capita and steel scrap are analyzed from 2010 to 2030. Based on Chinese situation, the most reasonable variation trend of China's steel production is proposed, which will increase from $626.7 \mathrm{Mt}$ in 2010 to approximately $914 \mathrm{Mt}$ in 2020, then gradually decrease to about $870 \mathrm{Mt}$ in 2030. Steel stocks per capita will increase from $3.8 \mathrm{t} /$ cap in 2010 to $8.09 \mathrm{t} /$ cap in 2020 (the inferior limit of completing industrialization), then reach $11.46 \mathrm{t} /$ cap in 2030 and stabilize. The peaks of energy consumption and $\mathrm{CO}_{2}$ emissions in steel industry are expected to reach 505.37 Mtce and 1444.1 Mt in 2020, respectively. The scrap ratio is expected to reach 0.36 by 2030, when steel scrap resources will be relatively sufficient. This paper can provide corresponding theoretical basis for the government to make decision-making of macro-control.
\end{abstract}

Keywords scenario analysis; steel production; peak value; industrialization level

\section{Introduction}

As one of the most important basic industries in China, steel industry plays an important support role in economic and social development. With the rapid development of the Chinese economy, steel production and consumption have grown significantly since 2000. If the trend of steel production in the long term can be accurately forecasted through analyzing the status quo of steel industry in China, the government can timely adopt regulatory measures and enact relevant countermeasures, which can improve foresight and reduce blindness to ensure the stabilization and equilibrium of industrial economy. China is currently the largest global

Received February 26, 2016, accepted April 19, 2016

*Corresponding author

Supported by the National Natural Science Foundation of China (71373003) 
steel producer and consumer. In 2014, crude steel production reached $823 \mathrm{Mt}$, nearly $49.4 \%$ of the world's steel production ${ }^{[1]}$. Moreover, the rapid expansion of the steel industry has increased energy consumption, resulting in environmental pollution and large amounts of greenhouse gas emissions. In 2014, the steel industry accounted for approximately $15 \%$ of the total energy consumption and ranked as the third-largest emitter of greenhouse gases in China, following the power and construction material sectors ${ }^{[2]}$. Raw materials for steel production consist mainly of its mineral and recycled resources. Although iron ore resources are rich in China, they are unevenly distributed and difficult to extract because of their location deep within the earth's crust, which significantly affects the development of the steel industry ${ }^{[3]}$. Because of the growing global demand for steel, particularly in China, an iron ore resource supply crisis has emerged. The numerous merits of steel scrap as an important steelmaking resource include its high energy efficiency, low carbon emissions, and easy recycling. For the sustainable development of the iron and steel industry, greater attention should be paid to the application of steel scrap in the steelmaking process. Making full use of steel scrap resources can also play a key role in alleviating the pressure on mineral demands. Steel scrap recycling can lead to a significant reduction in iron resource waste and environmental pollution. Therefore, it is of strategic importance to analyze and forecast China's future steel demand and the availability of depreciated steel scrap to provide theoretical basis for national policy-making.

Numerous analysis and prediction for China's steel demand trends have been conducted. The variation trends of China's future steel production are mainly divided into three categories: First, steel production peaks around 2015. Ma, et al. ${ }^{[4]}$ applied integrated assessment approach combining the stock-based model, the China-TIMES model and the co-benefits analysis model and concluded China's steel demand would increase from 625Mt in 2010, to approximately $800 \mathrm{Mt}$ in 2015 , and then gradually decrease to about $405 \mathrm{Mt}$ in 2050. Gao and Wang ${ }^{[5]}$ concluded steel demand in China would peak at around $670-700 \mathrm{Mt}$ in 2015 by analyzing the close relationship between steel consumption and steel stocks per capita, economic structure, urbanization rate, infrastructure, the level of social wealth accumulation. Zhang ${ }^{[6]}$ thought steel production would reach its peak in 2015. The steel industry is currently in a difficult situation and the best period of adjusting structures and upgrading. Second, steel production peaks around 2020. Tong, et al. ${ }^{[7]}$ built a system dynamics model to forecast and analyze $\mathrm{CO}_{2}$ emissions in China's steel industry in the future under various scenarios. The simulation results indicated China's steel production would reach its peak in 2022 at $723 \mathrm{Mt}$; while the peak of energy consumption and $\mathrm{CO}_{2}$ emissions in China's steel industry would reach in 2013, 457 Mtce and $1277 \mathrm{Mt}$, respectively. Yin and Chen ${ }^{[8]}$ suggested steel demand in China would rise from $600 \mathrm{Mt}$ in 2010 to a peak of $753 \mathrm{Mt}$ in 2025 , and then gradually decrease to $510 \mathrm{Mt}$ in 2050 through analyzing steel consumption of construction, machinery, automobiles, shipbuilding, railways, petroleum, household appliances containers and other industries individually based on stock based models. Xu and Wang ${ }^{[9]}$ calculated total crude steel production in China which referred to crude steel consumption per capita of America and Japan, then modified it based on the actual status of China. Results indicated that steel production in China would still increase in the next more than ten years and peak in 2020 at $710-738 \mathrm{Mt}$. Chen, et al. ${ }^{[10]}$ used system dynamics model and bottom-up energy system model to analyze steel demand, energy 
consumption and $\mathrm{CO}_{2}$ emissions in China's steel industry from 2010 to 2050. The results suggested that steel production in China would rise from $627 \mathrm{Mt}$ in 2010, to its peak of $772 \mathrm{Mt}$ in 2020, and then gradually decrease to $527 \mathrm{Mt}$ in 2050. Third, steel production peaks after 2030. Fridley, et al. ${ }^{[11]}$ forecasted that China's future steel production would be $804 \mathrm{Mt}$ in 2020 and peak at $831 \mathrm{Mt}$ in 2030, respectively, using several assumptions on drivers such as infrastructural and construction demand as well as demand for steel product used in appliances, machinery, and other products for final consumption. Hasanbeigi, et al. ${ }^{[2]}$ calculated the average annual growth rate of the steel production in the periods of 2010-2030 and concluded that total steel production in China would reach $658 \mathrm{Mt}$ in 2020 and peak at $680 \mathrm{Mt}$ in 2030.

So many scholars have forecasted China's steel production but different results are obtained. Therefore, it is of strategic importance to forecast steel demand trends suited to China's national conditions. A historical analysis of crude steel production, steel scrap consumption, energy consumption, $\mathrm{CO}_{2}$ emissions in China's steel industry and steel stocks per capita in China are provided from 2000 to 2014. Scenario analysis based on QGT equation with same growth rate of GDP and various average annual decline rate of steel production per unit of GDP is adopted to forecast the variation trends of steel demand in China from 2010 to 2030. The variation trends of steel production, energy consumption, $\mathrm{CO}_{2}$ emissions, steel stocks per capita, scrap ratio under three different scenarios from 2010 to 2030 are analyzed. Based on the conditions in China, the best fit for China's steel demand tendency is provided in the future.

\section{Historical Data Analysis}

According to statistical and query data ${ }^{[13,14]}$, the variation trend of crude steel production, steel scrap consumption, and steel scrap consumption per ton of steel production from 2000 to 2014 are obtained (Figure 1). From 2000 to 2014, the average annual growth rate of steel production was $14.4 \%$. In 2014, China's crude steel production was $823 \mathrm{Mt}, 6.4$ times that of 2000. The crude steel production per capita existed certain gap between China and developed countries. It was $601.4 \mathrm{~kg} / \mathrm{cap}$ in China, the peak $646 \mathrm{~kg} /$ cap in the United States by 1973, 800 $\mathrm{kg} /$ cap in Japan by 2007 and $1263 \mathrm{~kg} /$ cap in Korea by 2008 ${ }^{[15]}$. At this stage, tech-economic indicators of China's steel demand improved continuously. With domestic steel construction requirement and the growth rate of steel production growing, steel production capacity is released with steel demand increasing. During 2000-2014, the average annual growth rate of steel scrap consumption in China was $8.5 \%$, which was far less than the growth rate of steel production. The average steel scrap consumption per ton of steel production was lower to $107 \mathrm{~kg} / \mathrm{t}$ in 2014 from $229 \mathrm{~kg} / \mathrm{t}$ in 2000 with the decline reaching $53 \%$. These results indicate that utilization of steel scrap has decreased in China. Steel scrap has recently become a main alternative resource to iron ore. To alleviate resource crisis, countries around the world, particularly those in Europe, the United States, Japan, and other developed nations, have attached great importance to scrap recycling ${ }^{[16]}$. Steel scrap consumption in 2014 totaled $62 \mathrm{Mt}$ in the United States, 36.9 Mt in Japan, 91.3 Mt in the European Union (EU)-27, and 88.3 Mt in China. The proportion of steel scrap used in steelmaking was more than $75 \%$ in the United States, more than $35 \%$ in Japan, and more than $55 \%-60 \%$ in EU-27, whereas it was $10.7 \%$ in China ${ }^{[17,18]}$. Because of these challenges, the consideration of effective measures is critical. It is important to preserve 
existing iron resources while simultaneously promoting and applying advanced manufacturing techniques in ore dressing, smelting, and processing. Moreover, reducing steel production and increasing the utilization of steel scrap will help to reduce the consumption of non-renewable steel resources.

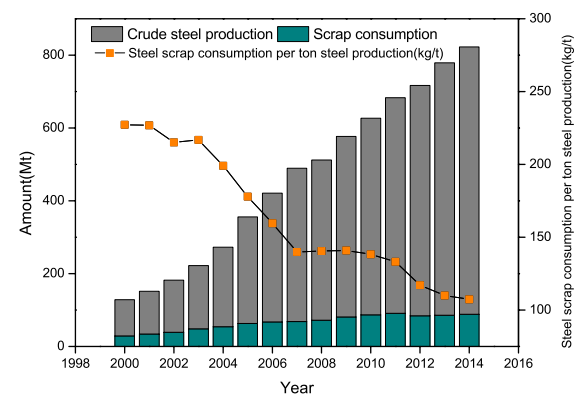

Figure 1 Trend of crude steel production, steel scrap consumption, and steel scrap consumption per ton of steel production

With the rapid development of steel production, energy consumption and $\mathrm{CO}_{2}$ emissions in China's steel industry has also increased. The changing trends of energy consumption and $\mathrm{CO}_{2}$ emissions in steel industry from 2000 to 2014 are shown in Figure 2. The comprehensive energy consumption per ton steel and total energy consumption of China's steel industry was $920 \mathrm{kgce} / \mathrm{t}$ and $118 \mathrm{Mtce}$ in $2000^{[19]}$ while $584.7 \mathrm{kgce} / \mathrm{t}$ and $481 \mathrm{Mtce}$ in $2014^{[20]}$. The decline of the comprehensive energy consumption intensity reached $52 \%$ from 2000 to 2014 . The ratio of energy consumption in steel sector to that of the eight major energy-consuming industries rose from $18.73 \%$ to $26.8 \%$, indicating an average annual growth rate of $10.7 \%^{[21]}$. The average annual growth rate of $\mathrm{CO}_{2}$ emissions in steel industry was $8.6 \%$ from 2000 to 2014 . In 2014, $\mathrm{CO}_{2}$ emissions in steel industry was $1360 \mathrm{Mt}, 3.05$ times that of 2000. From the perspective of carbon emissions per ton steel, $\mathrm{CO}_{2}$ emissions per ton steel in steel industry was $2580 \mathrm{~kg} / \mathrm{t}$ in $2000^{[22]}$ and $1657 \mathrm{~kg} / \mathrm{t}$ in $2014^{[23]}$, with the decline reaching $35.8 \%$. These results indicate that the energy-saving's emission reduction has made marvelous achievements in China's steel industry for worldwide carbon emissions. However, China's energy consumption and $\mathrm{CO}_{2}$ emissions are still inevitably large and growing quickly because of the continuous economic and social development ${ }^{[24]}$. Compared with $1300 \mathrm{~kg}$ of $\mathrm{CO}_{2}$ emissions per ton steel in Germany, energy efficiency in China's steel industry is far lower than international level. In recent years, China's energy utilization makes remarkable progress with the application of advanced technology in the steel enterprises.

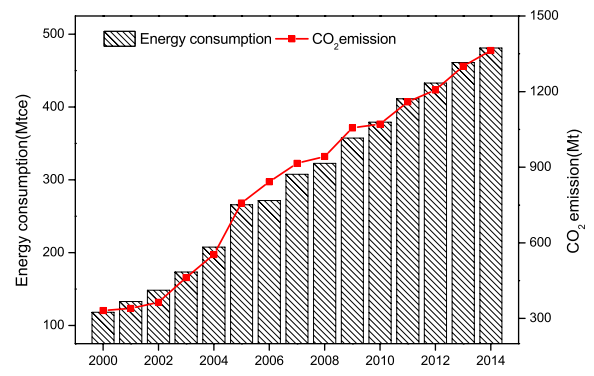

Figure 2 Trend of energy consumption and $\mathrm{CO}_{2}$ emissions in China's steel industry 
However, because of low concentration of steel industry, intensive energy consumption, low energy utilization efficiency, large greenhouse gas emissions, the rapid growth of steel production has inevitably led to a series of challenges related to resource availability and environmental issues. First, raw materials such as iron ore are in short supply. Currently, China is the global leader in steel production and consumption, contributing around $50 \%$ of iron and steel products worldwide ${ }^{[25]}$. Moreover, China accounts for more than $50 \%$ of the worlds total iron ore consumption ${ }^{[26]}$. Chinese iron ore consumption rose $486 \%$ between 2000 and 2014; the country has ranked in first iron ore consumption since $2003^{[27]}$. In addition, China is the leading importer of iron ore, accounting for about $60 \%$ of global total imports ${ }^{[28]}$. Because of the growing global demand for steel, particularly in China, an iron ore resource supply crisis has emerged. Steel production is a high-energy-intensive industry with high levels of greenhouse gas emissions ${ }^{[29]}$. Energy consumption and emissions are expected to increase in the future because of continuing production growth ${ }^{[30]}$.

Social steel stocks determine secondary or recoverable resources to a certain extent ${ }^{[31]}$. Steel stocks per capita was increasing from 1.29 tons per capita in 2000 to 5.44 tons per capita in 2014 with an average annual growth rate of $10.9 \%$ and its annual growth rate increased continuously in the years of 2000-2014 ${ }^{[32]}$. However, steel stock per capita is far lower than 8.8 tons in the United States, 10.5 tons in Japan and 7.6 tons in the Britain when the steel stocks reached the peak ${ }^{[33]}$. Obviously, the complete degree of infrastructure and construction and wealth accumulation is still low. In the future, infrastructure and construction will be further completed, wealth accumulation will also reach a high level.

\section{Scenario Definition}

Steel production per unit of GDP is an important evaluation index, which can analyze and measure the sustainable development of steel industry and even economic wellbeing in the region. Steel production (Q) is proportional to steel production per unit of GDP (T) under the condition that GDP $(\mathrm{G})$ is a constant. Moreover, energy consumption, material consumption and pollution are proportional to steel production per unit of GDP under the condition that all of GDP, energy consumption intensity, material consumption per ton steel and pollution per ton steel are constant. At last, the larger steel production per unit of GDP in a country, the higher ratio in steel sector to that of the total energy consumption, material consumption and pollution ${ }^{[34]}$. Whether steel production or energy consumption, material consumption and pollution in steel industry, and the ratio to that of the total country, those parameters should become the focus of people's concern.

This study based on the equation $\mathrm{QGT}^{[35]}$, which reflects the relationship of metal consumption and GDP. The relationship of steel production in the year and economic growth can be expressed as Equation (1):

$$
Q_{\tau}=G_{\tau} \times T_{\tau}
$$

where $Q_{\tau}, G_{\tau}, T_{\tau}$ stand for steel production in the year $\tau(t)$, GDP in the year $\tau$ (yuan), steel production per unit of GDP (t/yuan), respectively.

Steel demand is large in China for its vast population. In order to reduce the population 
influence on steel production, Equation (1) is modified as Equation (2):

$$
P_{\tau}=A_{\tau} \times T_{\tau}
$$

where $P_{\tau}, A_{\tau}$ stand for steel production per capita (t/cap) and GDP per capita (yuan/cap) respectively.

Obviously, the relationship of steel production and GDP is the same as the relationship of steel production per capita and GDP per capita when considering the population. In order to simplify analysis, the relationship of steel production and GDP is discussed in this study.

To simplify analysis, the average annual growth rate of GDP (g) and the average annual drop rate of steel production per GDP (t) are introduced ${ }^{[35]}$. Equation (1) can also be transformed as Equation (3):

$$
Q_{\tau}=G_{0}(1+g)^{\tau} \times T_{0}(1-t)^{\tau}=G_{0} T_{0}(1+g-t-g t)^{\tau},
$$

where $G_{0}, T_{0}$ stand for the base year's GDP and steel production per GDP, respectively.

From Equation (3), we can conclude that the change of steel production exists three possible states in the process of economic growth:

1) $g-t-g t>0$, that is $t<g /(1+g)$, steel production gradually increases;

2) $g-t-g t=0$, that is $t=g /(1+g)$, steel production remains unchanged, in such a case, $t$ can be expressed as $t_{k}$ (the critical value of $t$ );

3) $g-t-g t<0$, that is $t>g /(1+g)$, steel production gradually decreases.

Under the condition that the average annual growth rate of GDP keep unchanged, if steel production decreases, the average annual drop rate of steel production per GDP must be improved.

As shown in Equation (3), the average annual growth rate of GDP and the average annual drop rate of steel production per GDP codetermine the change of steel production. In three scenarios, the average annual growth rate of GDP is same and the year of 2010 is chosen as the base year. Based on the forecast of Chinese macro economy operation laboratory ${ }^{[36]}$, the average annual growth rate of GDP will keep 0.075 from 2010 to 2015, 0.07 from 2016 to 2020, 0.063 from 2021 to 2025 and 0.06 from 2026 to 2030. The average annual drop rate of steel production per GDP is adjusted in three scenarios (Table 1).

Table 1 Conditions setting for scenario analysis of economic growth and steel demand in China

\begin{tabular}{ccccc} 
Indices & $2010-2015$ & $2016-2020$ & $2021-2025$ & $2026-2030$ \\
\hline $\mathrm{g}$ & 0.075 & 0.07 & 0.063 & 0.06 \\
$t_{k}$ & 0.0698 & 0.0654 & 0.0593 & 0.0566 \\
$t$ in scenario 1 (S1) & 0.01 & 0.069 & 0.09 & 0.12 \\
$t$ in scenario 2 (S2) & 0.01 & 0.053 & 0.065 & 0.06 \\
$t$ in scenario 3 (S3) & 0.01 & 0.035 & 0.053 & 0.0566 \\
\hline
\end{tabular}

According to Equation (3) and the conditions setting in Table1, under the scenario 1: $t$ is 0.01 from 2010 to 2015 , that is $t<t_{k}$, steel production gradually increases, the growth is lower 
than the growth of GDP; $t$ is 0.069 from 2016 to 2020 , that is $t>t_{k}$, steel production gradually decreases; $t$ is 0.09 from 2021 to 2025 , that is $t>t_{k}$, steel production gradually decreases; $t$ is 0.12 from 2026 to 2030 , that is $t>t_{k}$, steel production gradually decreases.

Under the scenario 2: $t$ is 0.01 from 2010 to 2015, that is $t<t_{k}$, steel production gradually increases, the growth is lower than the growth of GDP; $t$ is 0.053 from 2016 to 2020, that is $t<t_{k}$, steel production gradually increases, the growth is lower and lower; $t$ is 0.065 from 2021 to 2025 , that is $t>t_{k}$, steel production gradually decreases; $t$ is 0.06 from 2026 to 2030 , that is $t>t_{k}$, steel production gradually decreases.

Under the scenario 3: $t$ is 0.01 from 2010 to 2015 , that is $t<t_{k}$, steel production gradually increases, the growth is lower than the growth of GDP; $t$ is 0.035 from 2016 to 2020, that is $t<t_{k}$, steel production gradually increases, the growth is lower than the growth of GDP; $t$ is 0.053 from 2021 to 2025 , that is $t<t_{k}$, steel production gradually increases, the growth is lower and lower; $t$ is 0.0566 from 2026 to 2030 , that is $t=t_{k}$, steel production remains unchanged, the growth of GDP is $6 \%$.

\section{Results Analysis}

\subsection{Steel Production}

According to the demanding forecast of steel product and quantitative scenario definition based on the future development of national economy, steel production is obtained under three different scenarios (Figure 3).

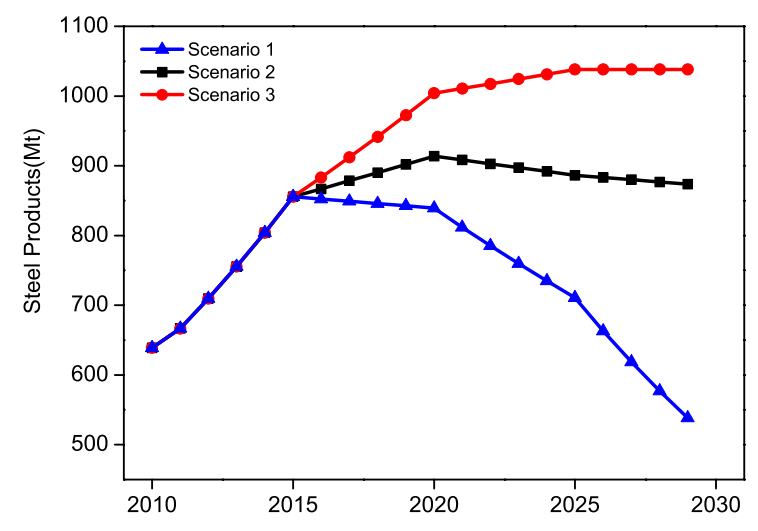

Figure 3 Steel production forecast for different scenarios, 2010-2030

Under the scenario 1, steel production in China is expected to peak in 2015 at 855.55 Mt. During 2010-2015, steel production is forecasted to increase at an average annual rate of $6.43 \%$. At this stage, China has become a steel superpower. However, because of unordered growth of steel production capacity, low industry concentration, high energy consumption, low economic benefit and serious environmental pollution, the derived contradictions in China's steel industry are increasingly prominent ${ }^{[37]}$. The government and the related departments have made unremitting efforts to eliminate outdated production capacity, reduce energy consumption, export more steel products and promote industrial transformation and upgrading. Chinese government has made some progress in strategic development for long term and improving industry ben- 
efits and international competition. At this stage, industrialization has not been completed in China. Economic growth of China still depends on industrial development, and the level of urbanization is much lower than it in developed countries ${ }^{[38,39]}$. During 2016-2030, steel production in China is expected to decrease at an average annual rate of $3.46 \%$. Finally, steel production is expected to reach $502 \mathrm{Mt}$ in 2030. At this stage, steel enterprises actively cope with operational difficulties caused by excess capacity, which results in the gradually deepening of the strategic readjustment in China's industrial structure. Meanwhile, to realize a decrease in steel consumption and innovative development, steel enterprises speed up the transformation and upgrading, endeavors to adjust the industrial structure and develop the alternative materials.

Under the scenario 2, steel production in China is expected to peak in 2020 at $914 \mathrm{Mt}$. During 2010-2020, steel production will increase at an average annual growth rate of $3.88 \%$ in China. At this stage, the economic structure and downstream steel industry will be optimized continuously. The proportion of secondary industry will decline steadily, and its proportion will also fall below that of tertiary industry ${ }^{[38]}$. In addition, the expansion rate of steel demand will decrease as well. At that time, steel production will gradually reach saturation in China. During 2021-2030, steel production in China will decrease at an average annual rate of $0.486 \%$. Finally, steel production will reach $870 \mathrm{Mt}$ in 2030. At this stage, both steel production and steel consumption per capita will exhibit a tiny decline. To meet the requirements of economic structural optimization, basic industries have to transfer. Moreover, the adjustment of industrial structure and the development of alternative materials result in a decrease in steel consumption $^{[40]}$.

Under the scenario 3, China's steel production will increase from 627 Mt in 2010 to approximately $1038 \mathrm{Mt}$ in 2030. At this stage, steel production continuously increases but the growth rate becomes more and more slow. China's steel industry can not timely adjust structure, fully utilize steel scrap resource and actively drive implementation of energy-saving emission reduction technology. To realize the low carbon development in steel industry, scientific decisionmakings are necessary, which are beneficial to the steel enterprises' survival and development ${ }^{[11]}$. Industrialization has been basically completed in China after $2030^{[24]}$, secondary industry decreases steadily and steel production will reach the peak periods and keep at a steady state subsequently.

\subsection{Energy Consumption and $\mathrm{CO}_{2}$ Emissions}

There is a strong correlation between $\mathrm{CO}_{2}$ emissions and energy consumption in steel industry, $\mathrm{CO}_{2}$ emissions mainly produce from energy consumption in the process of steel-making. Therefore, the analysis on $\mathrm{CO}_{2}$ emissions and energy consumption can be put together. Recently, numerous studies have shown that in addition to the industrial structure and technical level, carbon emissions from energy consumption are also closely related to the energy consumption scale and economic output ${ }^{[42]}$. Industrial technological progress is the indirect impetus for industrial structural evolution. It can be surmised that the world will not experience great progress in social science and technology similar to the recent technological revolution within the next 30 years. Therefore, scientific and technological progress can be maintained at $4.2 \%{ }^{[43]}$. We can obtain the influential coefficient of technical factor from the technological progress value 
is $95.8 \%$ (every five years), which can be converted into $99.15 \%$ annually ${ }^{[42]}$. Energy consumption includes coking coal, power coal, electric power, fuel oil and natural gas. Among these fuel, coal is used most in China's iron and steel industry. The comprehensive energy consumption intensity is $605 \mathrm{kgce} / \mathrm{t}$ in $2010^{[44]}$ and $\mathrm{CO}_{2}$ emissions of per ton steel is 1.71 tons $^{[23]}$ with 2010 as the base year. $\mathrm{CO}_{2}$ emissions and energy consumption under three scenarios are shown in Figure 4 .

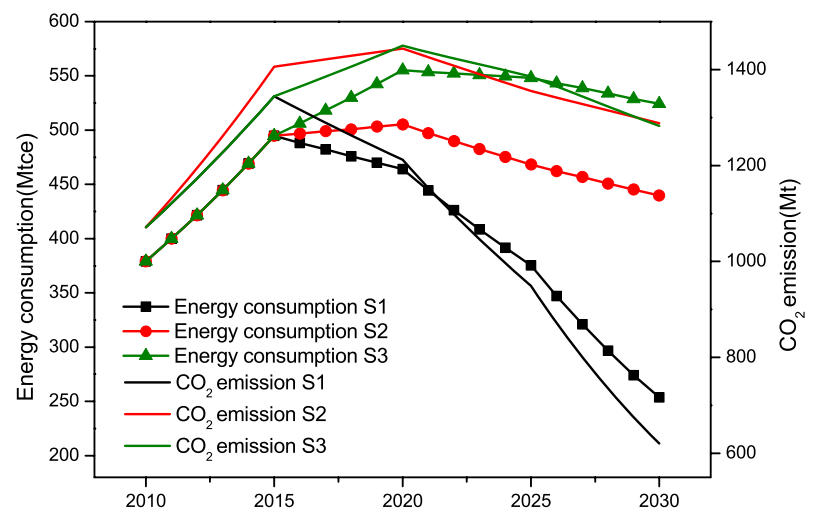

Figure $4 \mathrm{CO}_{2}$ emissions and energy consumption for different scenarios, 2010-2030

Increasing steel production was the main driving force for energy consumption before 2010 . After that, technological advancement will play a more important role in decreasing energy consumption. Under the scenario 1, energy consumption in steel industry increases from 379 Mtce in 2010 to 494.83 Mtce in 2015, and then decreases steadily to 253.61 Mtce in 2030. The average annual energy consumption is 21 Mtce and 102.7 Mtce lower than scenario 2, scenario 3 respectively (Table 2). The energy consumption peaks around in 2015 because of the calculated peak in steel output. The subsequent decline in energy consumption reflects the restructure of steel production and the improvement of energy efficiency.

Compared with the scenario 1, other two scenarios exhibit different annual energy consumption. Under the scenario 2, energy consumption will increase to 505.37 Mtce in 2020 slightly, and then decrease to 439.79 Mtce in 2030 rapidly, 186.18 Mtce higher than the scenario 1. However, under the scenario 3, energy consumption will increase to 555.26 Mtce in 2020, and then gradually decrease to 524.4 Mtce in 2030, 270.79 Mtce higher than the base scenario 1.

$\mathrm{CO}_{2}$ emissions in scenario 1 increases from 1071.6 Mt in 2010 to 1398.6 Mt in 2015. After that annual emissions keep decreasing and drop to an annual level of $716.8 \mathrm{Mt}$ by 2030 . A similar trend occurs in scenario 2, the growth rate will slow from 2015 to $2020, \mathrm{CO}_{2}$ emissions reach the peak at 1444.1 $\mathrm{Mt}$ in 2020. Due to the reduction of $\mathrm{CO}_{2}$ emissions intensity and technological progress, $\mathrm{CO}_{2}$ emissions in steel industry drop to $1288.5 \mathrm{Mt}$ in 2030 . In scenario $3, \mathrm{CO}_{2}$ emissions will reach its peak at $1569.4 \mathrm{Mt}$ by 2020 , then decrease to $1482.2 \mathrm{Mt}$ by 2030 , 290.1 Mt higher of average annual emissions in steel industry than scenario 1 from 2010 to 2030. 
Table 2 Energy consumption and $\mathrm{CO}_{2}$ emissions in China's steel industry under three scenarios

\begin{tabular}{|c|c|c|c|c|c|c|c|c|c|}
\hline & \multirow{2}{*}{$\begin{array}{l}\text { Effect } \\
\text { coefficient } \\
\text { of techno- } \\
\text { logical } \\
\text { progress }\end{array}$} & \multirow{2}{*}{$\begin{array}{l}\text { Comprehensive } \\
\text { energy } \\
\text { consumption } \\
\text { per ton } \\
\text { steel(tce/t) }\end{array}$} & \multicolumn{3}{|c|}{ Energy consumption /Mt } & \multirow{2}{*}{$\begin{array}{l}\mathrm{CO}_{2} \\
\text { emissions } \\
\text { per ton } \\
\text { steel }(\mathrm{t} / \mathrm{t})\end{array}$} & \multicolumn{3}{|c|}{$\mathrm{CO}_{2}$ emissions / $\mathrm{Mt}$} \\
\hline & & & $S_{1}$ & $S_{2}$ & $S_{3}$ & & $S_{1}$ & $S_{2}$ & $S_{3}$ \\
\hline 2010 & 1 & 0.605 & 379 & 379 & 379 & 1.71 & 1072 & 1072 & 1072 \\
\hline 2011 & 0.991 & 0.599 & 400 & 400 & 400 & 1.694 & 1121 & 1131 & 1121 \\
\hline 2012 & 0.982 & 0.594 & 422 & 422 & 422 & 1.679 & 1173 & 1195 & 1173 \\
\hline 2013 & 0.973 & 0.588 & 445 & 445 & 445 & 1.663 & 1227 & 1261 & 1227 \\
\hline 2014 & 0.965 & 0.583 & 469 & 469 & 469 & 1.650 & 1285 & 1332 & 1285 \\
\hline 2015 & 0.956 & 0.578 & 495 & 495 & 495 & 1.634 & 1344 & 1406 & 1344 \\
\hline 2016 & 0.947 & 0.572 & 488 & 497 & 506 & 1.619 & 1316 & 1414 & 1364 \\
\hline 2017 & 0.939 & 0.568 & 482 & 499 & 518 & 1.605 & 1290 & 1421 & 1386 \\
\hline 2018 & 0.93 & 0.562 & 476 & 501 & 530 & 1.590 & 1263 & 1429 & 1406 \\
\hline 2019 & 0.922 & 0.55781 & 470 & 503 & 542 & 1.576 & 1237 & 1436 & 1428 \\
\hline 2020 & 0.914 & 0.552 & 464 & 505 & 555 & 1.562 & 1212 & 1444 & 1450 \\
\hline 2021 & 0.905 & 0.547 & 445 & 497 & 553 & 1.547 & 1153 & 1426 & 1436 \\
\hline 2022 & 0.897 & 0.542 & 426 & 490 & 552 & 1.533 & 1099 & 1408 & 1423 \\
\hline 2023 & 0.889 & 0.537 & 409 & 483 & 551 & 1.520 & 1046 & 1390 & 1411 \\
\hline 2024 & 0.881 & 0.533 & 392 & 475 & 550 & 1.506 & 997 & 1373 & 1398 \\
\hline 2025 & 0.873 & 0.528 & 375 & 468 & 548 & 1.492 & 949 & 1355 & 1386 \\
\hline 2026 & 0.865 & 0.523 & 347 & 462 & 543 & 1.479 & 871 & 1342 & 1364 \\
\hline 2027 & 0.858 & 0.519 & 321 & 457 & 539 & 1.467 & 801 & 1328 & 1344 \\
\hline 2028 & 0.85 & 0.514 & 297 & 451 & 534 & 1.453 & 735 & 1315 & 1323 \\
\hline 2029 & 0.842 & 0.509 & 274 & 445 & 529 & 1.439 & 675 & 1302 & 1302 \\
\hline 2030 & 0.835 & 0.505 & 254 & 440 & 524 & 1.427 & 620 & 1288 & 1283 \\
\hline
\end{tabular}

\subsection{Social Steel Stocks Per Capita}

According to the materials balance, this year's steel stock includes crude steel production, minus exported steel, depreciated steel scrap, and unrecoverable sector. The average lifespan of steel products is 20 years gotten through the weighted average method ${ }^{[45]}$, which can make contribution to the calculation of scrap ratio. International Energy Agency ${ }^{[46]}$ predicted that the average lifespan of steel products would remain unchanged (20 years) for a few more decades. That is, steel products will turn into depreciated scrap after 20 years. Assuming the recycling rate of depreciated scrap is $58.9 \%$ for steel consumption and $15 \%$ for steel production used for net exports from 2010 to $2030^{[47,48]}$, social steel stocks per capita and annual growth were determined, as shown in Figure 5. 


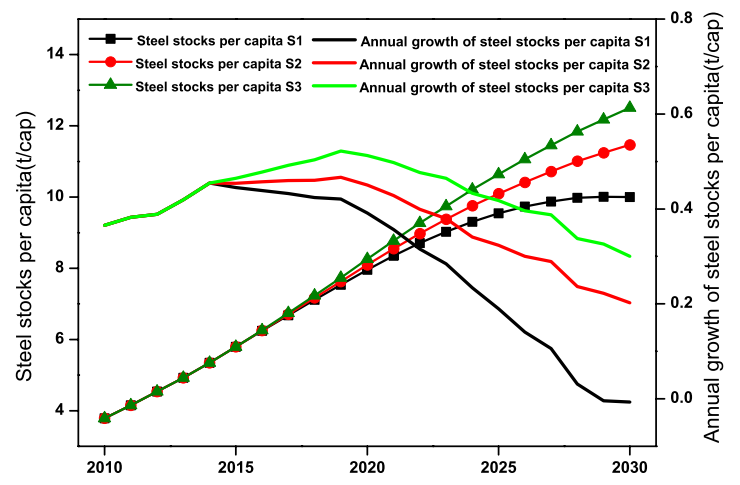

Figure 5 Trend of social steel stocks per capita and annual growth for different scenarios, 2010-2030

In 2010, the value of Chinese steel stocks per capita was $3.8 \mathrm{t} /$ cap and $8 \sim 12 \mathrm{t} /$ cap for industrialized countries ${ }^{[49,50]}$. When China completes industrialization, secondary industry is expected to decline steadily, with steel production expected to reach its peak ${ }^{[51-53]}$. China will have completed industrialization for its vast population when the value of steel stocks per capita reaches $8 \mathrm{t} /$ cap, which is the inferior limit.

In scenario 1 , the annual growth of steel stocks per capita reaches its peak at $0.45 \mathrm{t} /$ cap in 2014 and steel stocks per capita will reach $7.9 \mathrm{t} /$ cap in 2020, which is less than the limiting value of industrialization of $8 \mathrm{t} /$ cap. The amount of cast iron, cast steel, and mechanical and electrical product net exports are ignored because they are difficult to predict and have little effect on steel stocks per capita. Steel stocks per capita are expected to reach $10 \mathrm{t} /$ cap in 2030 and stabilize. At this stage, wealth accumulation will have reached a high level, and the requirements of infrastructure and construction will have been met. In developed areas with a preferable degree of industrialization, per capita steel demands tend to be maintained at a high level, and steel consumption can greatly promote sustainable local economic development.

In scenario 2 and scenario 3, the annual growth of steel stocks per capita reaches peak at $0.45 \mathrm{t} /$ cap and $0.51 \mathrm{t} /$ cap in 2020. Steel stocks per capita are expected to reach $8.09 \mathrm{t} /$ cap and $8.26 \mathrm{t} /$ cap in 2020, stabilize at $11.46 \mathrm{t} /$ cap and $12.51 \mathrm{t} /$ cap, respectively in 2030 .

\subsection{Scrap Ratio}

Steel scrap is a significant strategic material and a critical resource for sustainable development in steel industry, which concerns national economy and people's livelihood. With China's steel production ranking the world, the integrated recycling usage of steel scrap has become one of the most widely discussed fields in the 21 st century. To evaluate the availability of depreciated steel scrap, the scrap ratio ${ }^{[54]}$ is introduced. Among depreciated steel scrap, self-produced depreciated scrap is generated from the domestic social steel stock and can be continually supplied, whereas imported depreciated steel scrap is dependent on overseas markets and is therefore not guaranteed. Thus, the scrap ratio is used herein and defined as the domestic depreciated scrap recycled in the steel industry for use in steel production during the same statistical period, which reflects the adequacy degree of domestic depreciated scrap in steel industry. Depreciated scrap recycled is equal to the final steel product consumption in the region $\delta \tau$ (average lifespan of steel products, and $\delta \tau=20$ ) in past years (see section 4.3) 
multiplied by the recycling rate of depreciated scrap, expressed in Equation (4) as

$$
\rho_{\tau}=\frac{\alpha_{\tau} M_{\tau-\delta \tau}}{Q_{\tau}}
$$

where $\rho_{\tau}, \alpha_{\tau}, \delta \tau, M_{\tau-\delta \tau}$, and $Q_{\tau}$ stand for the scrap ratio in the year $\tau(t / t)$, recycling rate of depreciated scrap in the year $\tau(\%)$, average lifespan of steel products (y), steel products consumption in the region $(\tau-\delta \tau)$ in past years $(t)$, and steel production in the year $\tau(t)$, respectively.

The scrap ratio is calculated by Equation (4) under three scenarios, as shown in Figure 6 . In scenario 1, steel production is expected to peak in 2015 at $855.55 \mathrm{Mt}$ while the scrap ratio is just $0.07 \mathrm{t} / \mathrm{t}$. This ratio is expected to remain at a low level with small fluctuations before 2020, which indicates China is severely lacking in scrap resources. During 2020-2030, steel production will still decline, and the amount of depreciated scrap will rapidly increase. The aforementioned phenomenon will cause an exponential growth of scrap ratio, which is forecast to be as high as $0.63 \mathrm{t} / \mathrm{t}$ in 2030 . That is, China will have abundant depreciated scrap resources in accordance with the trend of steel production under the scenario 1.

In scenario 2, the trend of scrap ratio display similar characteristics with scenario 1 from 2020 to 2030. This ratio is expected to reach $0.36 \mathrm{t} / \mathrm{t}$ with abundant steel scrap resources. In scenario 3, with increasing steel production the scrap ratio will increase from $0.07 \mathrm{t} / \mathrm{t}$ in 2010 to $0.3 \mathrm{t} / \mathrm{t}$ in 2030. Steel scrap resources will be a little insufficient under the condition that steel production continuously grows from 2010 to 2030. In this scenario, serious resources and environmental issues will emerge in a few decades.

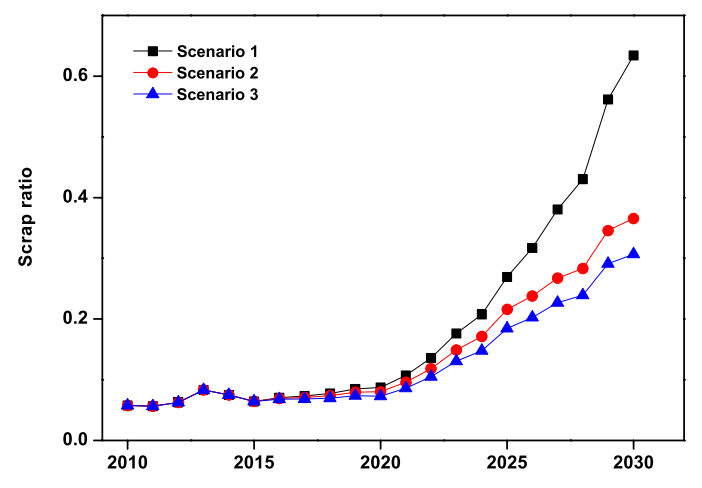

Figure 6 Variation of scrap ratio with time for three scenarios, 2010-2030

\section{Discussion}

With industrialization and urbanization process continuously deepening in China, steel demand in China will keep long-term development momentum. In initial stage of industrialization, steel production increases fast because completing national infrastructure construction needs massive steel. Comparatively complete infrastructure and the rapidly increased ratio of high-tech industries and tertiary industrial output-value causes that the growth rate of steel production gradually slows down even experiences negative growth ${ }^{[55]}$. According to the aforementioned assumption, the average annual growth rate of GDP will decrease to $6 \%$ in 2030 
from $7.5 \%$ in 2010. The rapid development stage of China's steel industries will not come back for the falling economic growth rate and the transformation of economic development pattern. However, China's urbanization rate was $54.77 \%$ in $2014^{[56]}$, which had a greater developmental space compared with developed countries. When developed countries' steel production reaches their peak, the urbanization rate is generally more than $70 \%$. Meanwhile, steel consumption per capita was $510 \mathrm{~kg} /$ cap, lower than $690 \mathrm{~kg} /$ cap in the United States, $880 \mathrm{~kg} /$ cap in Japan and $625 \mathrm{~kg} /$ cap in Germany ${ }^{[57,58]}$. Throughout the development course of steel industry in the world, steel production would reach the history peak when industrialization was basically completed in developed countries like Europe, the United States, Japan ${ }^{[59,60]}$. By reference to the successful experiences in developed countries, steel production will also reach the peak when industrialization is basically completed in China. During the "Twelfth Five-Year Plan" period, crude steel production is limited by iron ore and raw material, the growth is still lower than the "Eleventh Five-Year Plan". During the later stage of "Thirteenth Five-Year Plan", steel production will reach its peak around 2020, from then on production will steadily decline ${ }^{[61]}$. Therefore, along with China continues to push forward industrialization and urbanization, the domestic demand for steel products will continue to increase but with a low growth rate from 2010 to 2020. When China complete industrialization in $2020^{[50,62,63]}$, steel production will also reach its peak at the same year. Trend of steel production and the peak in scenario 2 conforms with China's basic national conditions compared with other two scenarios.

Total energy consumption and $\mathrm{CO}_{2}$ emissions in steel industry will be affected by steel production. In the following analysis, one important assumption is that all scenarios have the same degree of technological advancement, such as the comprehensive energy consumption intensity and $\mathrm{CO}_{2}$ emissions intensity. In a sense, such an assumption can avoid uncertainty which help researchers focus on analyzing the differences between scenarios which is mainly due to different steel production.

Scenario 1 has the lowest rate of energy consumption and $\mathrm{CO}_{2}$ emissions but with the biggest burden of reducing emissions under three different scenarios. Energy efficiency cannot be substantially improved in a short time because industrial structural adjustments and advanced technology application still need a long term. In scenario 3, energy intensity and $\mathrm{CO}_{2}$ emissions intensity is higher than tolerance of resources and environment in China ${ }^{[21]}$.

From the perspective of steel stocks per capita, three scenarios are expected to reach the limiting value of industrialization of $8 \mathrm{t} / \mathrm{cap}$. Steel demand and the growth rate of steel stocks per capita will be synchronously reached the peak when China will complete industrialization by reference to steel industry development in developed countries ${ }^{[64]}$. According to aforementioned data and three indicators, scenario 2 corresponds to China's basic national conditions.

From the perspective of scrap ratio, China will have abundant depreciated scrap resources based on steel production decreasing in scenario 1. However, it is inconsistent with the previous analysis. In scenario 3, steel scrap resources will be a little insufficient with continuous increase of steel production. In a few years, we will have to confront an increasing crisis of resource and environment.

Considering the above factors, scenario 2 corresponds to China's basic national conditions. China's steel demand will increase from 626.7 Mt in 2010, to approximately $914 \mathrm{Mt}$ in 2020, 
and then gradually decrease to about $870 \mathrm{Mt}$ in 2030. Steel stocks per capita are expected to reach $8.09 \mathrm{t} /$ cap with the average annual growth peak at $0.45 \mathrm{t} /$ cap in 2020 and stabilize at $11.46 \mathrm{t} /$ cap in 2030 .

\section{Conclusion}

On the basis of statistical calculations, the variation trend of crude steel production, energy consumption in steel industry, $\mathrm{CO}_{2}$ emissions, steel stocks per capita, the scrap ratio from 2000 to 2014 is obtained. The average annual growth rate of steel production and steel scrap consumption in China was unmatched at $14.4 \%$ and $8.5 \%$, respectively, which resulted in inadequate steel scrap resources and a decrease in steel scrap consumption per ton steel. Meanwhile, steel industry made remarkable progress in energy utilization and application of advanced technology. However, because of low concentration of steel industry, intensive energy consumption, poor economic performance, large greenhouse gas emissions, all those issues are prominent with the rapid development of steel production.

The average annual growth rate of steel stocks per capita was $10.9 \%$, which has great augment potentials compared with developed countries. Scenario analysis based on QGT equation with GDP growth unchanged and the various average annual decline rate of steel production per unit of GDP is adopted to analyze the variation trends of steel demand and corresponding to four principal factors changes in China under three different scenarios from 2010 to 2030. Combining the national condition, this paper concludes the most reasonable variation trend of China's steel production will peak in 2020 at approximately $914 \mathrm{Mt}$, then gradually decrease to about $870 \mathrm{Mt}$ in 2030. Steel stocks per capita will reach $8.09 \mathrm{t} /$ cap, which indicates China will complete industrialization in 2020, then stabilize at $11.46 \mathrm{t} /$ cap in 2030. Energy consumption and $\mathrm{CO}_{2}$ emissions will reach the peak at 505.37 Mtce and 1444.1 Mt in 2020, respectively. The scrap ratio is expected to reach $0.36 \mathrm{t} / \mathrm{t}$ with abundant steel scrap resources. At that time, steel scrap resources will basically meet the demand of steelmaking.

\section{References}

[1] Raw Materials Industrial Department. Operation and outlooks of iron and steel industry in 2014. The People's Republic of China ministry of industry and information technology, 2015, http://www.miit.gov.cn/ $\mathrm{n} 11293472 / \mathrm{n} 11293832 / \mathrm{n} 11293907 / \mathrm{n} 11368223 / 16445215$.

[2] Insight of China industry. Energy consumption of iron and steel industry. Beijing Liben Information Technology Company Limited, 2015, http://www.51report.com/invest/3058447.

[3] Wu X C. The research of China's iron ore resources supply security. Wuhan University of Technology, 2011.

[4] Ma D, Chen W Y, Yin X, et al. Quantifying the co-benefits of decarbonisation in China's steel sector: An integrated assessment approach. Applied Energy, 2016, 162: 1125-1237.

[5] Gao X R, Wang A J. The prediction of China's steel demand based on S-shaped regularity. Acta Geoscientica Sinica, 2010, 31(5): 645-652.

[6] Zhang G N. The steel output in peak period. China's steel news, 2015, http://www.csteelnews.com/xwzx/ djbd/201501/t20150116_270251.

[7] Tong H F, Qu W S, Liu Y. System dynamic scenarios analysis of $\mathrm{CO}_{2}$ emissions of China iron and steel industry. Chinese High Technology Letters, 2010, 20(5): 524-530.

[8] Yin X, Chen W Y. Trends and development of steel demand in China: A bottom-up analysis. Resources Policy, 2013, 38: 407-415.

[9] Xu X, Wang Y. Discussion about peak value of Chinese steel consumption. Metallurgical Information Review, 2007, 1: 4-10. 
[10] Chen W Y, Yin X, Ma D. A bottom-up analysis of China's iron and steel industrial energy consumption and $\mathrm{CO}_{2}$ emissions. Applied Energy, 2014, 136: 1174-1183.

[11] Fridley D, Zheng N, Zhou N, et al. China Energy and Emission Paths to 2030. Lawrence Berkeley National Laboratory, Berkeley, CA, 2011.

[12] Hasanbeigi A, Jiang Z Y, Price L. Why the energy use of Chinese steel industry may peak as early as 2015? ECEEE Summer Study on Energy Efficiency in Industry. European Council for an Energy Efficient Economy, 2014, 261-271.

[13] Editorial Board of China Iron and Steel Industry Yearbook. China iron and steel industry yearbook 19812013. China General Print Company, Beijing, 1981-2013.

[14] Liu S Z. Brief review of Steel scrap industry operation status in 2014. Iron and Steel Scrap of China, 2015, (1): $12-15$.

[15] Wang B. When crude steel production will reach the peak in China? Steel Group Counseling, 2014, http://info.glinfo.com/14/0728/14/E9E2C1BD5784F303.

[16] Junichiro O, Keigo A, Toshimasa T. Long-term global availability of steel scrap. Resources, Conservation and Recycling, 2013, 81: 81-91.

[17] Kong D Q. Insight into steel scrap situation and trend from the world evolving patterns in ten years. Poker investor, 2015, http://mt.sohu.com/20150617/n415219617.

[18] Liu S Z. The development of steel scrap industry in the new normal. World Metal Bulletin, 2015-06-23 (B15).

[19] Lan D N. Suggestions of China's steel industry energy efficiency targets and perfect index system. China Steel, 2007, (9): 19-27.

[20] Zhou L. The comprehensive energy consumption intensity decline by $1.22 \%$. Economic Daily, 2015, http://paper.ce.cn/jjrb/html/2015-02/04/content_231132.

[21] Lin B Q, Wang X L. Carbon emissions from energy intensive industry in China: Evidence from the iron \& steel industry. Renewable and Sustainable Energy Reviews, 2015, 47: 746-754.

[22] Zhao Y Q, Li X C, Li G J. Current situation of $\mathrm{CO}_{2}$ emission and point sources distribution in China's iron and steel industry. Journal of Iron and Steel Research, 2012, 24(5): 1-9.

[23] Wang K, Wang C, $\mathrm{Lu} \mathrm{X} \mathrm{D,} \mathrm{et} \mathrm{al.} \mathrm{Abatement} \mathrm{potential} \mathrm{of} \mathrm{CO}_{2}$ emissions from China's iron and steel industry based on LEAP. Journal of Tsinghua University, 2006, 46(12): 1983-1986.

[24] He J K. An analysis of China's $\mathrm{CO}_{2}$ emission peaking target and pathways. Advances in Climate Change Research, 2014, 5: 155-161.

[25] World Steel Association. World steel committee on economic studies. World Metal Bulletin, 2015.

[26] Ma W M, Zhu X X, Wang M M. Forecasting iron ore import and consumption of China using grey model optimized by particle swarm optimization algorithm. Resources Policy, 2013, 38(4): 613-620.

[27] World Steel Association. World steel committee on economic studies. World Metal Bulletin, 2013.

[28] World Steel Association. Steel Statistical Yearbook, Brussels, 2001-2014.

[29] Burchart-Korol D. Life cycle assessment of steel production in Poland: A case study. Journal of Clear Production, 2013, 54(1): 235-243.

[30] Shanghai Metal Market. China Issues 12th Five-year Development Plan for the Iron \& Steel Industry. Shanghai Non-ferrous Nets Information Technology Company Limited, 2011, http://www.metal.com/ newscontent $/ 26076$.

[31] Yue Q, Wang H M, Lu Z W. Quantitative estimation of social stock for metals $\mathrm{Al}$ and $\mathrm{Cu}$ in China. Transactions of Nonferrous Metals Society of China, 2012, 22(7): 1744-1752.

[32] Editorial Board of China Iron and Steel Industry Yearbook. China iron and steel industry yearbook 2015. China General Print Company, Beijing, 2015.

[33] World Steel Association. Variation trend of global steel stocks and consumption structure. World Metal Bulletin, 2014.

[34] Lu Z W, Yue Q, Gao C K. Study on steel output per unit GDP and steel production, energy consumption, materials consumption and wastes emission of steel industry. Engineering Sciences, 2013, 15(4): 23-29.

[35] Yue Q, Hou L M, Wang H M, et al. Quantifying social stock of metal substance and its relationship with economic output. Journal of Northeastern University (Natural Science), 2013, 34(2): 257-260.

[36] Li Y. Potential growth rate is 5.7\% from 2016 to 2020. Cai Xin Net, 2014, http://www.1caixin.com.cn/ article-277937html. 
[37] Yang W H. Reduction development of the new normal in steel industry. Chinese economy information, 2015, (535): 56-57.

[38] Guo L J. Iron and steel industry development cycle and the peak output of crude steel in China. Science Technology and industry, 2011, 11(3): 224-227.

[39] He C F, Chen T M, Mao X Y, et al. Economic transition, urbanization and population redistribution in China. Habitat International, 2016, 51: 39-47.

[40] Wang Y J. Steel industry life cycle and steel output forecasting for China. Forecasting, 1994, (5): 16-20.

[41] Yu B, Li X, Qiao Y B, et al. Low-carbon transition of iron and steel industry in China: Carbon intensity, economic growth and policy intervention. Journal of Environmental Sciences, 2015, (28): 137-147.

[42] Gao Z Y, Wang Y. Decomposition analysis of changes in industrial energy consumption in China. Statistical Research, 2007, 24(3): 52-57.

[43] Du Q, Chen Q, Lu N. Forecast of China's carbon emissions based on modified IPAT model. Acta Scientiae Circumstantiae, 2012, 32(9): 2294-2302.

[44] Ministry of Industry and Information Technology. The comprehensive energy consumption intensity in 2015. Bai da Net, 2012, http://steel.baidajob.com/article-366786.

[45] Xuan Y N, Yue Q. Forecast of steel demand and the availability of depreciated steel scrap in China. Resources, Conservation and Recycling, 2016, 109: 1-12.

[46] International Energy Agency. World Energy Outlook, Paris, 2008.

[47] Wang P, Jiang Z Y, Geng X Y, et al. Quantification of Chinese steel cycle flow: Historical status and future options. Resources, Conservation and Recycling, 2014, 87: 191-199.

[48] Bu Q C. Substance flow analysis and its application in steel industry. Northeastern University, 2005.

[49] Müller D B, Wang T, Duval B. Patterns of iron use in societal evolution. Environmental Science and Technology, 2011, 45(1): 182-188.

[50] Pauliuk S, Wang T, Müller D B. Moving toward the circular economy: The role of stocks in the Chinese steel cycle. Environmental Science and Technology, 2012, 46(1): 148-154.

[51] Yuan L. Analysis on characteristics of developed countries' steel production peak. Technoeconomics and Management Research, 2007, (1): 45-46.

[52] Li K, Dai L H, Han S. The life curve and peak forecasting of china steel industry. Industrial Economics Research, 2005, (4): 38-43.

[53] Liu T M, Zhai Q G, Zhou W, et al. China's iron ore demand prediction model and its application. China Mining Magazine, 2007, 16(2): 7-11.

[54] Zhang J H. Studying on zinc cycle and regeneration index of depreciated zinc products in China. Northeastern University, 2007.

[55] Wang D W. Opinions concerning development of iron and steel industry in China. China Metallurgy, 2003, (11): 8-13.

[56] China Economic Net. Urbanization rate is $54.77 \%$ in China by 2014. State Statistics Bureau, 2015, http://www.ciudsrc.com/new_chengshihualv/gedi/2015-01-20/79954.

[57] World Steel Association. Global steel consumption per capita dropped for the first time in five years by 2014. World Metal Bulletin, 2015-6-09 (F02).

[58] Shao LG, Qiao B. The study on demand changes tendency of energy and resources in the process of industrialization. Industrial Economy, 2015, (5): 41-51.

[59] Editorial department of Metallurgy Management. Analysis of the construct of the European Union, USA and Japan's iron and steel industrial organizational structure adjustment. Metallurgy Management, 2013, 5: $4-14$.

[60] Hong G. Research of the low carbon development of Japan steel industry. Ji Lin University, 2012.

[61] Yuan M, Kang Y B, Liu Q, et al. Analysis of $\mathrm{CO}_{2}$ emission trends and mitigation paths from China's steel and iron industry in 2020. Energy and Environment, 2012, 34(7): 22-26.

[62] Tarr D G. The steel crisis in the United States and the European Community: Causes and adjustments. University of Chicago Press, Chicago, 1988.

[63] Hatayama H, Daigo I, Matsuno Y, et al. Outlook of the world steel cycle based on the stock and flow dynamics. Environmental Science and Technology, 2010, 44(16): 6457-6463.

[64] Pauliuk S, Wang T, Müller D B. Steel all over the world: Estimating in-use stocks of iron for 200 countries. Resources, Conservation and Recycling, 2013, 71: 22-30. 